UDK: 621.3.049.77

DOI: https://doi.org/10.24867/12BE46Mrkaic

\title{
REALIZACIJA APLIKACIJE ELEKTROKARDIOGRAFA ZA DETEKCIJU SRČANIH ANOMALIJA
}

\section{REALISATION OF THE ELECTROCARDIOGRAPHIC APPLICATION FOR DETECTION OF HEART ANOMALIES}

\author{
Nebojša Mrkaić, Fakultet tehničkih nauka, Novi Sad
}

\begin{abstract}
Oblast- ELEKTROTEHNIKA I RAČUNARSTVO
Kratak sadržaj - Ovaj rad opisuje kako će se kreirati aplikacija koja će uspešno detektovati srčane probleme osobe koja ga koristi. Definisana su stanja poput ubrzanog rada srca, usporenog rada srca, normalnog rada srca $i$ prestanka rada srca. Takođe je ubačena $i$ statistika broja otkucaja srca, prosečan broj otkucaja u minuti kao i grafičko prikazivanje srčanog ritma.
\end{abstract}

Ključne reči: EKG, infarkt, obrada signala, stres, srce, zdravlje.

Abstract - This paper describes how the application is going to be created that detects heart failures and anomalies. Those failures are defined as increased heart rate, decreased heart rate, normal heart rate and no heart rate. Heart statistics is also implemented with graphic display of heart rhytm.

Keywords: ECG, heart attack, signal processing, stress, heart, health.

\section{UVOD}

U današnjem svetu ljudi ne obraćaju pažnju na svoje zdravlje pošto je svet dosta promenjem i ubrzava se život iz dana u dan. Zbog toga okreću se nezdravom životu ne zato što oni hoće već zato što su primorani. Takođe, broj penzionera se iz dana $u$ dan povećava pošto se kvalitet života poboljšava i životni vek se produžava.

U njihovim situacijama, postoje periodi života kada su usamljeni i nemaju nikog ko da vodi računa o njima. Svi ti primeri mogu da pokažu da je potrebno svetu da se osloni na naprednu tehnologiju ne samo po pitanju zanimacije i poslova već i povodom zdravlja. A u zdravlju, najčešće nam strada organ koji nije u mogućnosti da se regeneriše a bez njega ne možemo - srce.

Rad srca je izuzetno bitan da je na maksimumu jer na osnovu njega naše telo dobija hranljive materije koje su mu non stop potrebne.

Takođe, veoma veliki broj bolesti se pojavljuje iz situacije kada srce ne funkcioniše kako treba. Zbog svega toga, ova aplikacija bi nam omogućila da deo zdravlja kontrolišemo iako imamo srčanih oboljenja ili smo u potpunosti zdravi.

Da bismo započeli kreiranje aplikacije, potrebno nam je znanje iz više oblasti pošto je ova aplikacija hibridnog karaktera. Dok moramo poznavati medicinu i kako naše

\section{NAPOMENA:}

Ovaj rad proistekao je iz master rada čiji mentor je bio Platon Sovilj. telo funkcioniše, moramo isto tako biti upućeni $u$ hardverske komponente elektrokardiograma i računara. Takođe, moramo znati i softvere elektrokardiograma i računara, odnosno signal sa elektrokardiograma i pisanje koda na računaru. Kada se skupi određeno znanje iz tih oblasti, tada se može pristupati sa biomedicinarske strane koja obuhvata sve navedene oblasti od elektrotehnike, preko medicine do programiranja.

Najkompleksniji deo aplikacije jeste kako uspeti na osnovu jednostavnog elektrokardiografskog signala izvršiti klasifikaciju u svoju odgovarajuću grupu. Svaki srčani problem predstavlja poseban problem koji se mora tretirati posebno na svoj način. Nikako se ne sme doći u opciju da dođe do pogrešnog klasifikovanja srčanog signala jer time dolazi do pogrešne upotrebe lekova koji mogu da ne doprinesu nikakav boljitak, a čak može da dođe i do pogoršavanja stanja.

Zbog toga se mora veoma precizno sa dovoljno predznanja konstruisati ova aplikacija da ne bi imala mogućnost otežanja osobi koja već ima problema sa srcem.

\section{ELEKTROKARDIOGRAF}

Elektrokardiograf je uređaj koji registruje i beleži električnu aktivnost na površini kože koja nastaje kao posledica rada srca (Slika 1.). EKG (Elektro Kardio Gram) je grafički prikaz električne aktivnosti koju ispisuje elektrokardiograf. On meri promenu potencijala na elektrodama postavljenim na površini kože u blizini srca. EKG je važno dijagnostičko sredstvo u lečenju mana i oboljenja srca, kao i naravno za potvrdu normalnog stanja - zdravlja srca.

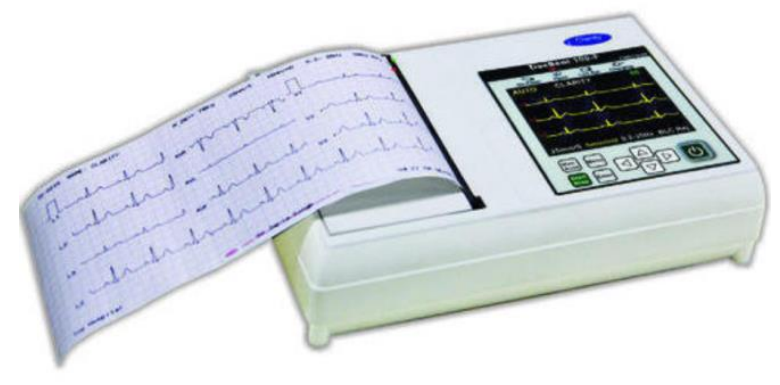

Slika 1. Elektrokardiograf

U konvencionalnom 12-kanalnom EKG-u, postavlja se 10 elektroda - na ekstremitetima pacijenta i na površini grudnog koša. 
Ukupne veličine električnog potencijala srca se zatim mere iz 12 različitih uglova (,vodova”), a snima se u određenom vremenskom periodu (obično 10 sekundi).

\section{EKG SIGNAL}

Prosečno srce čoveka otkuca otprilike oko sto hiljada puta tokom dana. Mnoge srčane tegobe počinju da se dešavaju tako što poremete par otkucaja srca tokom dana, što ne bi predstavljao veliki zdravstveni problem, ali u budućnosti može da ima fatalne posledice.

Tih par otkucaja (slika 2.), mogu da eksaliraju, i još ako se dodaju drugi faktori poput prekomernog umora $\mathrm{i}$ konzumacija određenih supstanci (alkoholnog pića, slatkih sokova..), rezultat svega toga može da dovede do prestanka rada srca. Pogotovo, ako gledamo na specifične slučaje i osobe koje konzumiraju narkotike i druga sredstva koja nanose štetu organizmu.

Zbog toga, da bi izbegli takve incidente, potrebno je što pre na što sigurniji način otkriti da li se zdravstveno stanje osobe pogoršava, da bi se mogle preduzeti određene mere da mu se sačuva život. Osobe koje su u komi, ili im je život ugrožen, su prikačeni na EKG.

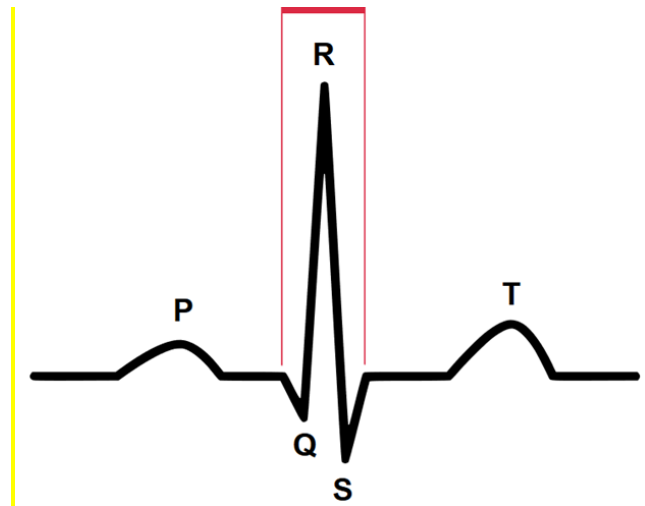

Slika 2. Elektrokardiografski snimak jednog otkucaja

Na signalu mogu da se uoči razlika u određenim delovima signala, i svaki taj segment predstavlja određen deo rada srca.

P talas predstavlja atrialnu depolarizaciju. Tada krv ulazi u srce, odnosno u pretkomore u PR intervalu.

QRS se odnosi na ventrikularnu depolarizaciju, odnosno kada srce ispumpava krv i šalje je telu. Q talas reaguje na depolarizaciju, $\mathrm{R}$ talas je najveći jer se tada dešava kontrakcija. S deo obeležava finalni deo depolarizacije. QRS kompleks je najbitniji.

ST interval predstavlja nulti period između polarizacije i depolarizacije ventrikula.

T talas se odnosi na ventrikularnu depolarizaciju.

\section{SRČANA OBOLJENJA}

Pre svega, da bi se vršila korektna klasifikacija, potrebno je saznati o kakvim se oboljenjima radi i šta sve možemo da očekujemo povodom njih (slika 3.). Prvenstveno, srčana oboljenja koja su navedena na slici ispod se razlikuju po lokaciji na kom oboljenje nastaje, pored čega dolazi i do ispitivanja nivoa ozbiljnosti navedenih oboljenja.

Miokardialna infarkcija je poznat kao srčani napad kada oštećen deo srca napravi prekid protoka krvi na osnovu zagušenja. To zagušenje može da bude uzrok zgrušavanja krvi, što opet može da prourokuje mnogo faktora, od alkoholizma, preko nervoze do prekomerne težine osobe.

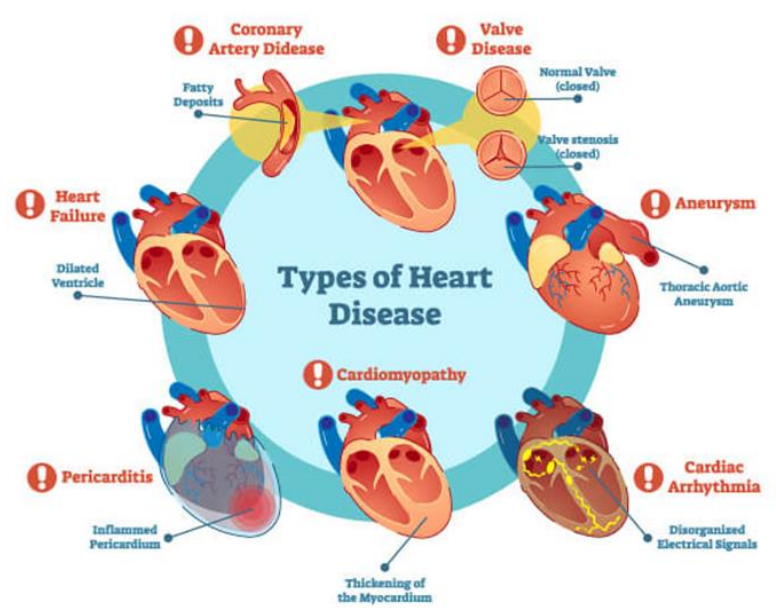

Slika 3. Srčana oboljenja

Bolest srčanih valvi, kojih ima četiri i locirane su u svakoj srčanoj komori i odgovorne su za odvođenje i dovođenje krvi unutar srca, odnosno predstavljaju kapiju između komora i pretkomora srca.

Valvularna stenoza se može klasifikovati u bolest srčanih valvi, gde ne dolazi do kompletnog širenja valvi i samim time dolazi do slabijeg protoka i otkazivanja srca.

Kardiomiopatija predstavlja fizička povreda srca, gde dolazi da srčano mišićno tkivo slabi, a pošto je to neregenerativni organ poput jetre, počinje da izvršava svoju funkciju nepotpuno (sl. 3). Tada u levoj ventrikuli dolazi do podebljanja srčanog zida što otežava protok krvi a samim time smanjuje aktivnost date osobe i postavlja je $u$ nezgodan položaj. Na slici se može videti zadebljanje srčanog zida, a unutra se može primetiti da je došlo da velike štete srčanog tkiva, koje nema pravilan oblik srca, već je povređen deo tkiva razgranat poput drveta.

Perikardialna bolest napada srčanu maramicu koja okružuje srce uglavnom zbog određenih infekcija i virusa povodom zapaljenja disajnih puteva. Kada osoba dobije upalu pluća (rheumatoid arthritis), ili mu se desi nešto slično, ukoliko ne bude vodio računa, može da se zapaljenje proširi i na druge organe, kao u ovom primeru, na srce.

\section{IZRADA APLIKACIJE}

Za početak smo pristupili programskom paketu Matlab gde smo prvenstveno kreirali GUI (Graphic User Interface) i započeli smo sa implementacijom izgleda $\mathrm{i}$ funkcionalnost naše aplikacije. Za početak imali bi dugme start koje pokreće aplikaciju i dugme stop koje zaustavlja aplikaciju. Dok je aplikacija aktivirana, jedino što možemo da uradimo jeste da zaustavimo aplikaciju ili da izađemo iz aplikacije. Ostale opcije smo onemogućili za korišćenje. Tada smo dodali parametre povodom broja ukupnih otkucaja i vremena. Tada, uz pomoć konstantne evidencije vremena i otkucaja dobili bi otkucaje po minuti na osnovu kojih bi vršili separaciju otkucaja po grupama. Da bi pacijent imao bolji utisak da aplikacija korektno radi i da on može vizuelno da isprati rad njegovog srca, 
ubačen je grafik, gde mu x osa predstavlja dužinu signala dok mu y osa predstavlja jačinu signala. Uz sve te parametre, ubačeno je i srčano stanje koje je trenutno prisutno.Takođe, postojao bi i detektor za srčane napade, koji bi sa trigerovanjem dugmeta i audia obavestio korisnika i osobe u okolini korisnika. Nakon svih tih implementacija, aplikacija ima dati izgled (slika 4.),

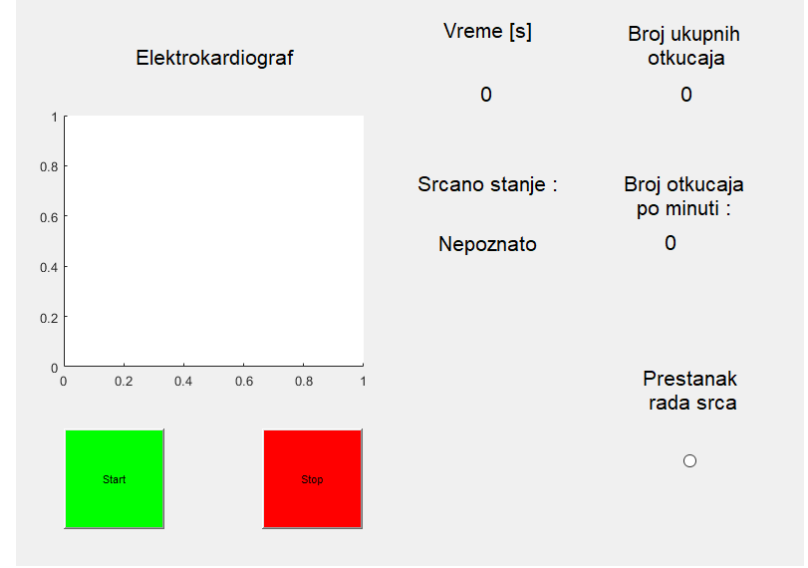

Slika 4. Aplikacija za detektovanje srčanih anomalija

\section{PROŠIRIVANJE APLIKACIJE}

Nakon što smo uspešno ispodešavali i implementirali vizuelan deo aplikacije, potrebno je da se i softverski implementira, odnosno da se definiše šta će tačno da se dešava. Za početak signal koji se dovodi jeste signal sa elektrokardiograma i potrebno je napisati kod koji uspešno obrađuje dati signal. Za početak signal koji dolazi je podeljen u dva paketa, gde bi se prvi paket prikazao na prvoj polovini grafika, a drugi paket bi se prikazao na drugom delu grafika. Kada bi došao nov deo signala, drugi paket prelazi na mesto prvog paketa, a nov paket dolazi na mesto drugog paketa i time dobijamo kontinualan prikaz signala sa elektrokardiograma. Plavi signal predstavlja paket jedan a paket dva predstavlja narandžasti signal (Slika 5.). Na aplikaciji će biti kontinualan prikaz otkucaja srca.

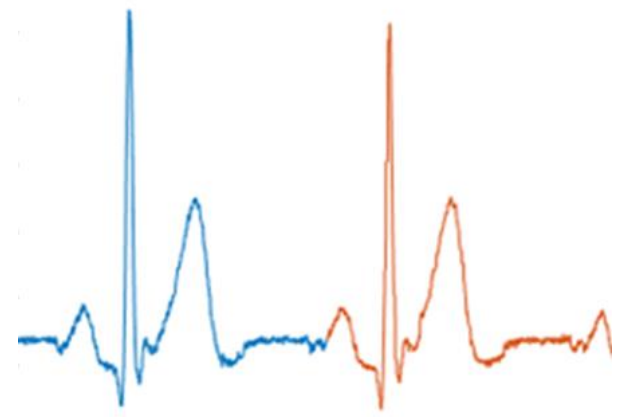

Slika 5. Prikazivanje kontinualnosti signala preko paketa

Sledeći korak u programiranju jeste detektovati tačno jedan otkucaj srca, i ne detektovati artefakte i šumove. $\mathrm{Na}$ osnovu eksperimentalne faze, na određenoj jačini bi se završavao QRS kompleks koji je najvidljiviji u srčanom ritmu.

Iz tog jednog ritma bi se uzela samo jedna vrednost i na osnovu nje bi se izvršila evidencija u brojaču da se desio jedan otkucaj. Ukoliko je jačina slabija, to ne može da se konstantuje kao otkucaj pošto nema dovoljnu jačinu.

\section{DEFINISANJE OPSEGA}

Od izuzetnog je značaja postaviti pragove u kodu. Za početak, svi signali blizu nule i iznad vrednosti otkucaja srca su odsečeni i podešeni na neutralnu vrednost 0 . Onda smo postavili granice u separaciji ritma srca. Ritam srca koji je normalan se nalazi u opsegu između 60 i 100 otkucaja po minuti. Ukoliko je ritam ubrzan i prelazi preko 100, tada ulazimo u proces tahikardije. Ukoliko srce usporeno radi i padne ispod 60 otkucaja po minuti, tada ulazi u stanje bradikardije.

\section{TESTIRANJE APLIKACIJE}

Kada je aplikacija startovana pritiskom na dugme start, ona počinje sa izvršavanjem. Vrednost na grafiku dostiže do 0.005 , na osnovu koje vrednosti smo uspeli targetirali vrh QRS kompleksa. Ukoliko QRS kompleks ne bude zadovoljavao određenu visinu, ono neće biti registrovano kao otkucaj, što predstavlja problem.

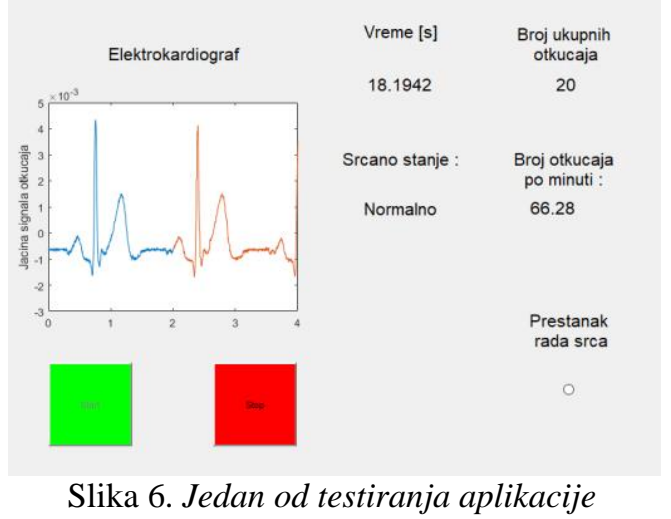

Vreme je postavljeno da ispisuje i poslednje 4 decimale zbog tačnosti, a broj otkucaja po minuti sadrži poslednje dve decimale (slika 6). Srčano stanje je normalno i broj ukupnih otkucaja je vidljiv, ali je zato elektrokardiografski snimak prikazan iz dve boje da bi se prikazivao kontinualno.

Odnosno, prvo je obrađen prvi paket signala koji sadrži 1000 vrednosti, i postavljan je u oblast na $\mathrm{x}$ osi između vrednosti 2 i 4 . Nakon toga, obrađuje se sledećih 1000 vrednosti. Tada, prvi paket signala se postavlja između vrednosti 0 i 2, a drugi paket se postavlja između vrednosti 2 i 4 . Odnosno, naredni paket će uvek biti prikazan desno, a prethodni paket levo, na osnovu čega dobijamo konstantno kretanje signala. Takođe, dužina paketa obrade se može promeniti što će uticati na brzinu otkucaja srca i menjanje signala. Ukoliko ima više vrednosti u jednom paketu, prikaz signala će biti sitniji.

\section{ZAKLJUČAK}

Nakon konstruisanja aplikacije i pisanje njenog koda, gde se na kraju taj kod manuelno testirao i uspešno je prošao sve korake, zaključak je da je aplikacija spremna za dalju esploataciju. Za aplikaciju bi se našla odgovarajuća hardverska postavka koja bi ispunjavala sve zahteve aplikacije sa svim senzorima, memorijama i displejima.

Aplikacija će takođe morati imati i određeno održavanje u slučaju ako se na njoj dese neželjene stvari (kvar, neregularan rad aplikacije..) i takođe da bi se usavršila aplikacija, moguće je i dopisivanje novog koda koji bi bio 
nadogradnja. Uz to bi bilo planirano da i uređaj sadrži odgovarajuć lek za pacijenta, da u slučaju mu se desi nešto neočekivano, i hitna pomoć ne bi stigla brzo, da taj lek uspe da pomogne osobi, i čak da mu spasi život. Osim toga, u planovima budućeg razvoja aplikacije, planira se njeno integrisanje sa istraživačkim sistemom za razvoj stohastičkog elektorkardiografa - elektrokardiografa koji će primeniti koncepte iz ranije razvijenih metoda digitalnog stohastičkog merenja [7-15].

\section{REFERENCE}

[1] „Heart Attack or Sudden Cardiac Arrest: How Are They Different?". www.heart.org. 30. Jul 2014.

[2] "Your Heart Failure Healthcare Team". www.heart.org.

[3] Marian, A. J.; Roberts, Robert (1. 4. 2001). „The Molecular Genetic Basis for Hypertrophic Cardiomyopathy". Journal of Molecular and Cellular Cardiology.

[4] Mark, Jonathan B. (1998). Atlas of cardiovascular monitoring. New York: Churchill Livingstone.

[5] Moyer, V. A. (2. 10. 2012). „Screening for coronary heart disease with electrocardiography: U.S. Preventive Services Task Force recommendation statement.”. Annals of Internal Medicine.

[6] Braunwald E. (ed) (1997), Heart Disease: A Textbook of Cardiovascular Medicine, Fifth Edition, p. 108, Philadelphia. W B Saunders Co.

[7] Vladimir Vujicic, Boris Licina, Dragan Pejic, Platon Sovilj, Aleksandar Radonjic: Stochastic measurement of wind power using a two-bit A/D converter, Measurement Volume 152, February 2020, 107184, ISSN 0263-2241, https://doi.org/10.1016/j.measurement.2019.107184

[8] Pejić D., Naumović-Vuković D., Vujičić B., Radonjić A., Sovilj P., Vujičić V.: Stochastic digital DFT processor and its application to measurement of reactive power and energy, Measurement, 2018, pp. 494-504, ISSN 0263-2241, https://doi.org/10.1016/j.measurement.2018.04.004

[9] M. Urekar, P. Sovilj, „EEG dynamic noise floor measurement with stochastic flash A/D converter", Biomedical Signal Processing and Control, Vol. 38, pp. 337345, Elsevier B. V, 2017, ISSN 1746-8094, https://doi.org/10.1016/j.bspc.2017.07.006

[10] Radonjic, A. ; Sovilj, P. ; Vujicic, V... Stochastic Measurement of Power Grid Frequency Using a Two-Bit A/D Converter , Instrumentation and Measurement IEEE Transactions on, 2014, Vol. 63 - issue 1, pp. 56-62, DOI: 10.1109/TIM.2013.2277515, ISSN 0018-9456

[11] Sovilj P. M., Milovančev S. S., Vujičić V.: Digital Stochastic Measurement of a Nonstationary Signal With an Example of EEG Signal Measurement, Instrumentation and Measurement IEEE Transactions on, 2011, Vol. 60 issue 9, pp. 3230-3232, ISSN 0018-9456, DOI: 10.1109/TIM.2011.2128670

[12] Pejić D., Gazivoda N., Ličina B., Urekar M., Sovilj P., Vujičić B.: A Proposal of a Novel Method for Generating Discrete Analog Uniform Noise, Advances in Electrical and Computer Engineering, 2018, Vol. 18, No 3, pp. 6166, ISSN 1582-7445, DOI: 10.4316/AECE.2018.03009

[13] P. Sovilj, B. Vujičić, M. Sokola, D. Pejić, Ž. Beljić, Z. Mitrović, ,Stochastic Measurement of Noise True RMS using 2-bit Flash A/D converters",Technical Gazette, Vol.24 No.5 October 2017, pp. 1315-1322, ISSN 13303651 (Print), ISSN 1848-6339 (Online), DOI 10.17559/TV-20151124100705

[14] Ž. Beljić, V. Vujičić, D. Pejić, M. Sokola, Z. Mitrović, P. Sovilj, „Grid Fundamental Harmonic Measurement in Presence of Gaussian Frequency Deviation Using 2-bit
Flash A/D Converter“, Technical Gazette, Vol.24 No.2 April 2017, pp. 481-488, ISSN 1330-3651 (Print), ISSN 1848-6339 (Online), DOI 10.17559/TV-20151109231714

[15] P. Sovilj, M. Milovanović, D. Pejić, M. Urekar, Z. Mitrović, Influence of Wilbraham-Gibbs Phenomenon on Digital Stochastic Measurement of EEG Signal over an Interval, pp. 270-278, Measurement Science Review, Vol. 14, No. 5, 2014, ISSN 1335 - 8871

\section{Kratka biografija:}

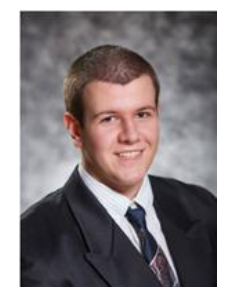

Nebojša Mrkaić je rođen 1995. godine u Novom Sadu. Završio je srednju školu Jovan Jovanović Zmaj 2014. godine u Novom Sadu, nakon čega je upisao Fakultet tehničkih nauka u Novom Sadu i diplomirao je 2019. godine. 